\title{
"Esto es lo que yo buscaba [...] el conocimiento de las yerbas, y su aplicación": sistematização e difusão dos conhecimentos sobre virtudesde plantas medicinais (América meridional, séculos XVII e XVIII)
}

Eliane Cristina Deckmann Fleck*

Roberto Poletto**

Resumo: Neste artigo, apresentamos o significativo processo de trocas culturais que se deu entre indígenas e missionários jesuítas na América meridional, nos séculos XVII e XVIII, com destaque para os saberes relativos às plantas medicinais e às práticas curativas. A análise das Cartas Ânuas da Província Jesuítica do Paraguai e da obra Materia Medica Misionera, escrita pelo irmão jesuíta Pedro de

\footnotetext{
* Doutora em História pela Pontifícia Universidade Católica do Rio Grande do Sul e Professora da Graduação e do Programa de Pós-Graduação em História da Universidade do Vale do Rio dos Sinos (Unisinos). Bolsista de Produtividade em Pesquisa-CNPq. E-mail: ecdfleck@terra.com.br.

** Mestrando junto ao Programa de Pós-Graduação em História da Universidade do Vale do Rio dos Sinos (UNISINOS). Atuou como bolsista PIBIC-CNPq no projeto "Medicina e Missão na América Meridional: Epidemias, saberes e práticas de cura (séculos XVII e XVIII)", no período de fevereiro de 2010 a julho de 2011. E-mail: robertopoletto@hotmail.com
} 
"Esto es lo que yo buscaba [...] el conocimento...

Montenegro, em 1710, revelou o importante papel desempenhado por informantes, enfermeiros e copistas indígenas, tanto na identificação, coleta e nos experimentalismos com plantas nativas quanto na difusão e circulação dos conhecimentos médicos sistematizados pelos missionários da Companhia de Jesus. Palavras-chave: Companhia de Jesus. Cartas Ânuas. Mediadores culturais. Farmacopeia indígena. Materia Medica Misionera.

\section{Introdução}

A coleta e as experiências realizadas com ervas e raízes medicinais existentes nas imediações dos colégios e das reduções da Companhia de Jesus resultaram não apenas na instalação de herbários e no melhor atendimento de doentes, através das boticas, mas também na elaboração de tratados de medicina e de farmacopeia nativa. Nesses tratados, como o Matéria Medica Misionera, que analisamos neste artigo, constata-se que os espaços jesuíticos de formação e de missão na América meridional foram palco tanto da aplicação e avaliação da eficácia dos saberes europeus quanto de experimentalismos com plantas nativas e de trocas de saberes e práticas entre missionários e indígenas. Muitos destes conhecimentos - sobre medicamentos e práticas terapêuticas - foram compartilhados através da intensa correspondência que os missionários mantiveram entre si ou das cópias dos catálogos e receituários que fizeram circular entre as reduções e os colégios das Províncias Jesuíticas da América meridional e aqueles instalados na Europa e no Oriente.

\section{Que para esta terra venham aqueles que conhecem "algo de botica, medicina y enfermería"}

Durante os primeiros anos do século XVII, os missionários jesuítas "[...] con más buena voluntad que ciencia adecuada [...] actuaron como curanderos" (FURLONG, 1962, p. 604), levando aos doentes, além dos "consuelos espirituales [...] el alimento conveniente a su estado y las medicinas posibles”(HERNÁNDEZ, 1913, p. 16). É preciso considerar que dentre os missionários enviados a América meridional houve 
também aqueles que haviam tido a oportunidade de realizar "algunos estudios y alguna práctica quirúrgica en Europa" antes do seu ingresso na Companhia de Jesus, o que os habilitava a atuar como enfermeiros, "medio médicos", "herboristas", boticários e cirurgiões. Houve outros, no entanto, como o padre Antônio Sepp, que, pouco familiarizado com as artes de curar, viu-se obrigado a ordenar a realização de uma sangria durante a peste de varíola hemorrágica que se abateu sobre a redução de Nossa Senhora da Fé, no ano de 1695. O empenho na confecção de instrumentos sangradores mostrou-se insuficiente para controlar a epidemia, levando-o a afirmar que os métodos europeus eram impotentes para curar os enfermos ${ }^{1}$, que sentiam algum alívio apenas com "[...] Los remedios caseros e con los propios de la farmacopea indígena”. (SEPP apud ECHENIQUE; FERREIRA, 1985, p. 253-254).

Em carta enviada em 1702, o irmão Enrique Peschke, que desempenhava as funções de boticário no Colégio de Córdoba, parece confirmar a crescente importância que as "plantas en América” passaram a assumir nas terapêuticas curativas, apesar de observar que eram

[...] diferentes que en Europa, aún aquellas que en ambas partes tienen las mismas propiedades [...] lo que en Alemania es ancho y áspero, es aquí lanceolado y liso, lo que hay que extender también a otras propiedades externas, por lo que toca a las internas, son maravillosas (PESCHKE apud MUHN, 1951, p. 49).

A admiração dos jesuítas pela flora americana associava-se a certa inquietação, pois era preciso

[...] acceder al conocimiento exacto de sus propiedades y aprender a reconocer las plantas en el campo [...] recogerlas y cultivarlas, separando hojas y semillas, bayas de raíces, estudiando los jugos y las cocciones, los ungüentos y las pomadas. Un proceso complejo, que requería del ensayo y error y de un saber basado en la experiencia y en la razón, en la práctica y en la teoría. ${ }^{2}$ (DI LISCIA, 2002, p. 35) 
"Esto es lo que yo buscaba [...] el conocimento...

A questão que se colocava para os jesuítas que se dedicavam aos estudos de Botânica è̀ Medicina no início do século XVIII era, sem dúvida, "Cuál es la orientación a seguir [...] cuando la guía botánica es todavía la de Dioscórides y la medicina se debate entre el galenismo y la iatroquímica, entre Paracelso y el nuevo vitalismo?" Muitos deles estavam conscientes de que o sistema de classificação e a nomenclatura das plantas, a partir de suas qualidades galênicas, poderiam resultar em problemas de aplicação, dada "[...] la semejanza que suelen tener unas [plantas] calientes con frías, y cordiales con venenos", razão pela qual "[...] examinaban las propiedades de supuestos medicamentos probándolos una y otra vez, en diferentes pacientes y enfermedades, para determinar su utilidad" (DI LISCIA, 2002, p. 39-41). ${ }^{3}$ A adoção desses procedimentos fica, aliás, bastante evidente na obra Materia Medica Misionera ${ }^{4}$, escrita pelo irmão jesuíta Pedro Montenegro ${ }^{5}$, em 1710, e na qual se constata a influência exercida por Dioscórides ${ }^{6}$ e por Galeno ["filósofo y príncipe de la Medicina"] (MONTENEGRO, [1710], 1790, Prólogo) ${ }^{7}$.

Se a intenção de Montenegro era a de inventariar informações relativas às propriedades curativas das plantas medicinais nativas, ${ }^{8}$ consideradas fundamentais para a prática médica nas áreas de atuação da Companhia de Jesus, não deixa de registrar, todavia, informações sobre "estos pobres indios" com os quais estava em contato e, também, de tecer considerações sobre a qualidade do atendimento prestado aos doentes na então Província Jesuítica do Paraguai. Em relação a este último aspecto, esclarece que na Europa "[...] solo curan hombres capazes, y médicos y cirujanos aprovados, y que han pasado por claces de Theorica, y por maestros en practica, ó por hospitales en ambas materias" (MONTENEGRO, [1710], 1945, Prólogo), enquanto na América ${ }^{9}$ a situação era lastimável ${ }^{10}$, pois as pessoas estavam à mercê de:

[...] Médicos Curanderos y Curanderas; mas les cuadra el nombre de matasano, que el de Cirujano, y el de carnicero que el de medico, ó curandero, y son tantos y tantas los dados á esta secta de locos, que entre tal gana ganado poco ó nada hay que escoger, y cierto es, que á ellos les fuera mejor arar para sustentarse, y á ellas hilar la rueca, que ciegos y cargados 
de ignorancia, sin advertir el peligro de sus conciencias; ni los homicidios que hacen en los pobres enfermos, que como necesitados admiten el socorro, que estas sabandijas, ó casta de locos les ofrece, no con pequeño riesgo de sus vidas [...] (MONTENEGRO, [1710], 1945, Prólogo)

Além de atestar a reverência aos pressupostos hipocráticogalênicos, a avaliação que Montenegro faz do atendimento prestado por "médicos curanderos y curanderas" acaba por justificar o ofício "autor de Botica" - que ele viria a assumir. Contudo, à medida que avançamos nos capítulos da obra, os saberes indígenas, sobretudo sobre plantas medicinais e práticas curativas, assumem destacada importância, nem sempre reconhecida pelo irmão jesuíta, que prefere associá-los à providência divina. A manutenção de determinadas práticas curativas tradicionais nas reduções e o papel desempenhado por indígenas - como informantes ou enfermeiros, ou mesmo como curandeiros - ficam também evidentes na correspondência trocada entre os missionários e encaminhada ao Padre Geral da Companhia de Jesus, como procuraremos demonstrar neste artigo.

\section{A contribuição de informantes e "médicos índios expeditos y capaces en Farmacopea”}

Montenegro não apenas afirma que 'Tiene se por cosa sierta assi entre los autores Griegos como entre los latinos que el imbentor dela medicina fue solo Dios immortal y sierto va fundada en rason la tal aberiguacion", e que a cura se dá através, "daquel Sumo Architecto, fabricador de cielos e tierra” (MONTENEGRO, [1710], 1790, Prólogo), como atesta a intervenção divina através da presença e das qualidades de plantas encontradas nas regiões que circundavam as reduções. Em relação ao "araçay”, empregado - com êxito - nas "camaras de sangre", ele chega a dizer: "Pusso la Divina Providencia en estas tierras tan pobres de médicos y boticas, y la cria en tanta abundancia que hombres e animales se valen de ella para sustento y medicina [...]" (MONTENEGRO, [1710], 1790, p. 44). (grifos nossos) 
"Esto es lo que yo buscaba [...] el conocimento...

Assim, tanto a natureza quanto os conhecimentos indígenas sobre ela são percebidos como intervenção do Criador - que agia de diferentes maneiras para garantir sua utilização "como sustento $y$ medicina", como pode-se constatar nas passagens relativas ao uso da erva-mate, que "[...] en estos paises del Paraguay, y Misiones [...] la enseñó Santo Thomé á los Indios” (MONTENEGRO, [1710] 1945, p. 4), e cujas propriedades conducentes seriam bem superiores às do cacau do oriente. A utilização da erva-mate pelos indígenas era, dessa forma, legitimada em função da passagem do apóstolo São Tomé pela América, ocasião em que lhes ensinou a viver como cristãos civilizados e pregou sobre a "verdadeira religião"12.

Em outros momentos, a justificativa dada pelo jesuíta para a aceitação dos saberes indígenas estava ligada à condição e à conduta do informante. Ao falar sobre a planta altocigo, Montenegro ressalta várias de suas qualidades - provenientes de seu amargor - e sua aplicação em doenças nos olhos decorrentes de fraquezas no cérebro, acrescentando que havia tomado contato com esta planta através de um índio cristão muito qualificado, chamado Clemente, "[...] cierto Curuzúyara ó medico, el mas périto que en estas Misiones he ballado" (MONTENEGRO, [1710], 1945, p. 252). Na referência que faz às qualidades da raiz do Caápari guazú, empregada com sucesso nas epidemias de camaras de sangre, Montenegro afirma que, apesar de nunca ter feito experiências com a planta, dava algum crédito à informação, por ter sido dada por "[...] un capázy buen cristiano llamado Clemente” (MONTENEGRO, [1710] 1945, p. 314).

A confiança depositada nas informações dadas pelo "capaz. buen cristiano e el más perito" - o informante indígena Clemente - parece apontar para a associação que Montenegro faz entre conversão e conhecimento, como pode-se constatar em outra passagem na qual, ao descrever os usos possíveis da planta yacaré, ele destaca que os indígenas costumavam buscá-la, para neutralizar venenos de diversos animais e que "[...] así me la dió a conocer cierto Indio viejo, el más expedito que he ballado en estas Misiones en el conocimiento de las yerbas, y su aplicación" (MONTENEGRO, [1710], 1945, p. 118).

Por outro lado, as referências feitas aos conhecimentos dos nativos, sobretudo em relação à aplicação de plantas medicinais, no tratamento de doenças acabam por revelar o reconhecimento, tanto 
da farmacopeia americana quanto da atuação dos “médicos índios" pelo irmão jesuíta, como fica evidenciado nesta passagem, em que, ao descrever as propriedades do "bejuco", Montenegro ressalta ter recebido informações de "varios medicos Indios los más capaces" (MONTENEGRO, [1710], 1945, p. 209), o que aponta para o relevante papel desempenhado pelos informantes indígenas na elaboração da Materia Médica Misionera. Na descrição que faz de algumas das plantas, Montenegro acrescenta a informação de que podiam ser encontradas em "buertas y chacaras de los Indios", o que sugere - além de se tratar de um recurso terapêutico tradicional entre os indígenas - a continuidade de seu emprego nas reduções jesuíticas.

A identificação das plantas em guarani - e também em tupi parece atestar a importância que Montenegro dava ao conhecimento que os indígenas tinham sobre a localização e sobre as propriedades curativas das plantas nativas, bem como a sua preocupação em garantir que os leitores da Materia Medica Misionera - padres que se encontravam em outras reduções, colégios ou residências jesuíticas - pudessem contar com a ajuda de indígenas - informantes ou enfermeiros - para sua utilização como remédio em determinadas situações. Além disso, é preciso considerar que, apesar do relativo isolamento e das longas distâncias, padres, indígenas e informações circulavam entre as diferentes regiões da América, onde a Companhia de Jesus atuava, como depreende-se desta passagem em que Montenegro refere os usos da copaya pelos índios Tupis:

Me he informado de los Portugueses, y Tupis, que en el Brasil lo han sacado, y dicen, que hay arbolea muy gruesos, y en tierra pingüe, que en quince dias llenan dos calabazos, como dos frascos, y más, de los nuestros de á dos cuartillos de medida mayor (MONTENEGRO, [1710], 1945, p. 232).

Ou, então, na referência feita ao uso da "Macaguá isipo" no tratamento de mordidas de víboras que, segundo Montenegro, havia sido ensinado-lhe por um índio Tupi instalado no povoado de San Borja, que "[...] se vino de la Ciudad de San Gabriel buido, según me han dicho" (MONTENEGRO, [1710], 1945, p. 101). 
"Esto es lo que yo buscaba [...] el conocimento...

Também a engenhosidade indígena foi registrada por Montenegro, como pode-se constatar na descrição que faz da aplicação da planta "vivora de Tarija”. O irmão jesuíta informa que, inicialmente, suas propriedades eram conhecidas apenas por um espanhol, que não as revelava por "[...] el interéz que le corria”. O segredo, no entanto, acabou sendo revelado por um indígena - um caridoso cristão - que, muito perspicaz, observou-o - à distância - colher determinada erva após ser picado por uma cobra:

[...] al punto corrió á un vallecito de un arroyuelo, y un Indio tráz de él, vió que cojió esta yerba, la mascó y aplicó á la herida, y mascando mas tragó el zumo. Dicho Indio fué mas Cristiano, por que luego comunicó el secreto á un su compañero, y de aqui resultó el descubrimiento para conocer su preciosa virtud, y aquel secreto del codicioso europeo. Esto me lo contó dicho Pe. Tomas Moreno. (MONTENEGRO, [1710], 1945, p. 331) (grifos nossos)

Este registro possibilita a reflexão sobre três situações: a primeira, que parece revelar o uso de plantas medicinais nativas pelos não nativos, no caso, por um encomendero espanhol, que viria a ser descrito como "codicioso"; a segunda, que destaca a engenhosidade do indígena, que parecia desconhecer a flora da região onde se encontrava e que será descrito como "más cristiano"- na comparação com o espanhol -, e a terceira, que informa que o ocorrido em Tarija havia sido relatado ao irmão Montenegro - instalado no colégio de Córdoba - por outro padre, muito provavelmente, pelo jesuíta responsável pelo atendimento espiritual da região do noroeste da Argentina.

A existência de medicamentos estocados nas boticas de colégios ou reduções, bem como a circulação de conhecimentos que se dava entre as diferentes regiões de atuação dos missionários jesuítas fica evidente nesta passagem que extraímos da Ânua de 1720-1730:

Por colmo de desdicha, siguió después de tres meses otra epidemia, la cual había causado ya inmensos estragos en Lima y en Cuzco, ciudades principales del Perú. Por suerte nos habiamos ya provisto con una buena reserva de medicamentos, llegados 
de allá; asi se pudo cortar el contagio en Tarija, donde habían sido atacadas ya familias enteras, con la consiguiente molestia de los Padres que los tuvieron que auxiliar. (CARTAS ÂNUAS... 1720-1730, [1927], p. 129) (grifos nossos)

Montenegro registra, também, as incursões que fazia - acompanhado de indígenas - em busca de determinadas plantas que, por serem provenientes do Oriente, eram tidas como raras, tanto nos herbários quanto nas boticas europeias:

[...] muy diverso en figura es el que aquí doy por verdadero esquinanto del que nos dibuja Mathiolo Senense, y de sus obras nos da la copia Andrés de Laguna en su ilustración al comentario de Dioscórides, porque es la estampa propia que sacó de Mathiolo, por no tener Dioscórides más que el códice en Griego sin estampa [...] cierto pasto, ó paja aromática, que yo he hallado por estas Misiones, ni más ni menos que las que nos trajen de Meca, y cierto, que á no atender con sumo cuidado la hubiera cogido y usado por el esquinanto; pero viendo que le faltaba lo agudo y aromático que pide el verdadero esquinanto la arrojé, fiando del Todo Poderoso lo hallaría, y no me engañé, porque estando un día de gran Sol á la orilla de cierto arroyo á la sombra, á donde me guarneci del cansancio del largo camino que traía, me lo deparo el Todo Poderoso, por medio del olfato, y en fin después de varias diligencias mías, y de tres Indios que venían en mi compañía, registrando arboles, y mato de alrededor, hice reparo, que en sentándome en tierra por lo cual me puse á buscar entre las yerbas y pasto el tal olor, cuando el uno de los Indios me dijo: este es Capiî-cati. Dije le, si, [...] esto es lo que buscaba: saqué sus raices, y hallé por olor y gusto el verdadero esquinanto, de lo cual mucho me alegré. (MONTENEGRO, [1710], 1945, p. 83-84) (grifos nossos)

Como podemos constatar, mesmo sendo sobre um tratado médico, a Materia Medica Misionera parece comprovar não apenas a circulação de medicamentos e conhecimentos entre os jesuítas - através das cópias de tratados e receituários e da intensa 
"Esto es lo que yo buscaba [...] el conocimento...

correspondência que entre si mantiveram como também a interação de indígenas e missionários, como evidenciado no relato feito pelo irmão jesuíta Montenegro - que, depois de muito procurar, encontrara o verdadero esquinanto, com a ajuda de um indígena - e que aponta para as trocas culturais entre saberes e práticas de cura.

Se considerarmos as Cartas Ânuas ${ }^{13}$ escritas pelos missionários jesuítas nos séculos XVII e XVIII, constataremos que não apenas o conhecimento das propriedades curativas das plantas existentes no entorno das missões interessava aos missionários jesuítas. Preocupados em contornar os efeitos das epidemias, os padres decidiram recrutar um corpo de enfermeiros indígenas, os “curuzuyás”, que deveriam “[...] enterarse cada mañana si había algún enfermo en su respectivo barrio o cuartel y como andaban los que ya se sabia que estaban enfermos”. Cabia a eles fazer o diagnóstico e sugerir a medicação "según su saber y poder" e, inclusive, administrar todos "los sacramentos, el viático y extrema unción” (FURLONG, 1962, p. 613). De acordo com Hernández, os "curuzuyás" eram “[...] cuatro, seis ú ocho en cada pueblo y para que pudiesen ejercitar su cargo, estaban exentos de las tareas comunes, y aun les cultivaban su chacra los otros indios", para que pudessem preparar e levar "las medicinas convenientes" aos doentes (HERNÁNDEZ, 1913, p. 291-292).

$\mathrm{Na}$ Ânua de 1635-1637, encontramos registros do envolvimento dos indígenas, inclusive daqueles que haviam buscado atendimento nos colégios, em tarefas que cabiam aos enfermeiros: "[...] el personal que vive en el colégio, por atender a los apestados se contagian a raíz. de lo cual fallecen [...] las indias enfermas por su parte tenian que barrer las salas [...] limpiar los instrumentos de cirujía [...]" (CARTAS ÂNUAS 1635-1637 In: D.H.A., Tomo XX, 1927, p. 687), além de "freg [ar] los platos y pucheros en que comian y lava [r] las alhajas de los que morian" (FURLONG, 1962, p. 165). Também "los indios de la Congregación de Nuestra Señora acudían [...] a ejercitar su mucha caridad con los enfermos, a aderazarles las camas" (FURLONG, 1962, p. 612).

Se, por um lado, esses relatos revelam a presença - e a utilização, por consequência - de instrumentos cirúrgicos no colégio, bem como a preocupação em isolar os doentes, "[...] acomodados en una casa con sus repartimientos y camas", por outro, aponta para a inexistência de medidas para evitar o contágio, já que os doentes, além de circularem 
livremente pelo colégio, eram incumbidos de algumas tarefas. Cabe lembrar que, algumas vezes, os próprios missionários foram os agentes transmissores de doenças ao ingressarem nas aldeias com a intenção de convertê-los, ou, então, promoveram a disseminação das epidemias ao contornarem a falta de pessoal para o atendimento dos doentes com o envio às aldeias de "[...] un mancebo ya enfermo" (FURLONG, 1962, p. 611). Apesar de suprirem a falta de médicos e enfermeiros e do treinamento que muitos desses indígenas receberam para poderem atuar como tal, a avaliação que alguns jesuítas faziam sobre eles parece não ter se alterado significativamente, como se constata nesta passagem que relata que "Enfermóse allí el Padre Bonilla, y tuvo que sujetarse a un indio bastante rústico, el cual le cauterizó y sangró. Convalecido, se dedicó, como los demás, a su tarea apostólica" (CARTAS ÂNUAS 1652-54 [1994], p. 37). (grifos nossos)

\section{"Dio a luz su criatura, bautizada en seguida": pro- cedimentos empregados para aliviar as dores do parto}

No século XVIII, os missionários continuaram observando as instruções para a instalação das reduções, definidas em $1610^{14}$, como fica evidenciado na Carta-Relação de 1747, na qual o Pe. Cardiel aponta para uma preocupação em garantir a saúde dos indígenas, mediante $\mathrm{o}$ atendimento de algumas condições:

Para formar un pueblo se procura escoger una llanura de las calidades siguientes: $1^{\circ}$ ancha como un cuarto de legua y cerca de una milla para la extensión entre las calles. $2^{\circ}$ Algo eminente, así por huir de la humedad dañosa en estas tierras, como por gozar de aire más puro. $3^{\circ}$ Que no tenga cerca pantanos, de los cuales se engendran multitud de molestos mosquitos y sapos y víboras ponzoñosas. $4^{\circ}$ De buenas aguas cerca, asi para beber, como para lavarse y bañarse, a que es aficionado todo indio, y lo necesita para la salud. $5^{\circ}$ De buenos bosques, no distantes, para leña y para edificios. $6^{\circ}$ Que esté despejada por parte del Sur, para desembarazo del viento fresco, que acá, por estar en estotra zona, es el Sur, y es necesario en 
"Esto es lo que yo buscaba [...] el conocimento...

tierra de tantos calores [...] La tierra que tuviese más de estas calidades y conveniencias es la mejor [...] (CARDIEL apud FURLONG, 1953, p. 153-154). (grifos nossos)

A observância dessas recomendações não impedia, contudo, a ocorrência de epidemias, que acabaram por levar o padre Cardiel a construir "[...] cabañas alejadas de la aldea para evitar de este modo el contagio a los familiares de los enfermos" (CARDIEL apud FURLONG, 1953, p. 612-613), o que parece não ter sido tão eficiente, já que, apesar de ter posto "[...] guardas para que ninguno lo biciese [...] no obstante varios iban a escondidas y entraban en los aposentos de sus parientes, y juzgo que de estos casi todos murieron [...] para que se vea la cortedad de los indios" (CARDIEL apud FURLONG, 1953, p. 188).

Conforme as Ânuas da segunda metade do século XVII, as medidas para contenção do contágio tomadas pelos missionários em algumas reduções não foram suficientes para impedir os efeitos das epidemias sobre os indígenas de "las nascientes cristandades". As gestantes e parturientes mereceram especial atenção dos padres em seus registros, tanto em função da iminência da ocorrência de abortos quanto pela possibilidade de, através dos partos, ressaltar "la eficacia de la intercesión de nuestro Santo Padre [Ignacio]" (CARTAS ÂNUAS 1652-1654, 1927, p. 53). O receio de que as crianças recémnascidas não fossem batizadas e, assim, não tivessem assegurada a sua salvação, fazia com que os missionários destacassem situações como estas: "Dió a luz una criatura pequeña, pero viva. Apenas bautizada voló al cielo; mientras la madre sanó por completo" (CARTAS ÂNUAS 1652-1654, 1927, p. 53-54) e, ainda, "Ya por tres días sufría allí una pobre india de crueles dolores de parto; pero con el contacto con una reliquia de nuestro patriarca San Ignacio dio con bien a luz. su criatura, bautizada en seguida" (CARTAS ÂNUAS 1659-1660, 1927, p. 5) (grifos nossos). Na mesma Ânua, encontramos relato sobre mais um parto difícil e o nascimento de gêmeos:

Así experimentó el gran poder de San Ignacio una india, la cual ya por cuatro días sentía atroces dolores de parto. Ya no bubo esperanzas de que la criatura naciera viva, y ella mismo ya no esperaba sino la muerte... Asistió a la moribunda uno de 
nuestros Padres... Animó la a encomendarse a nuestro santo Padre Ignacio, aplicándole una reliquia del Santo Padre. Dio a luz en seguida a dos criaturas, las cuales, juntamente con su madre, están sanas y buenas. (CARTAS ÂNUAS 1659-1660, 1927, p. 41) (grifos nossos)

Em algumas Ânuas, encontramos registros que permitem especular sobre índices de mortalidade infantil, de fecundidade e de natalidade e, também, sobre o conhecimento que os jesuítas tinham da anatomia do útero e das etapas do parto. Numa delas, o padre informa que "Tuvo un hijo, el cual pronto voló al cielo. Al mismo tiempo murieron dos indias, cada una con niño de pecho [...]. Algunos meses más tarde volaron al cielo los dos; mientras ella, gravemente se enfermó de parto" (CARTAS ÂNUAS 1652-1654, 1927, p. 47). Na continuidade - e referindo-se a outra situação - ele diz que "Después de haber dado a luz a su séptimo hijo, estaba para morir una india; no pudiendo desprenderse de las secundinas [la placenta y membranas que envuelven el feto], pudriéndose ellas de un modo perceptible. Aplicó se le la efigie de San Ignacio, y se libró y sanó" (CARTAS ÂNUAS 1652-1654, 1927, p. 53) (grifos nossos).

$\mathrm{Na}$ Ânua de 1650-1652, encontramos relatadas duas situações de complicações surgidas durante o parto. Numa delas, a mulher "[...] estaba ya sufriendo por tres días, y agonizando, cuando se salvó su vida tocándola con la medalla de San Ignacio"; na outra, uma mulher "embarazada la primera vez, pero con un apostema maligno en al seno" foi socorrida pelo padre que lhe aplicou "una reliquia de nuestro Padre Ignacio. Nació bien el bijo, y sanó la madre por completo" (CARTAS ÂNUAS $1650-1652,1927$, p. 11). Em relação ao primeiro caso, o padre registra que "[...] habían ya auxiliado la moribunda", tendo sido chamado - tardiamente e apenas - para administrar os sacramentos (CARTAS ÂNUAS 1650-1652, 1927, p. 11) (grifos nossos). Quanto ao auxílio prestado à parturiente moribunda, é preciso considerar que as mulheres prestes a dar a luz contavam com o apoio - e o conhecimento - de indígenas parteiras, como constata-se nesta referência feita a elas na Ânua de 1659-1660: 
"Esto es lo que yo buscaba [...] el conocimento...

Habia otra moribunda de parto con hemorragia. Por su extremada debilidad estaba desabuciada por las parteras, diciendo ellas, que la criatura se habia muerto en el seno de ella. Auxiliaron a la moribunda con los últimos sacramentos de la Iglesia, y trajeron una reliquia de nuestro Santo Padre. Hizo entonces la mujer la promesa de comulgar por la fiesta de San Ignacio, en caso de escaparse del peligro. (CARTAS ÂNUAS 1659-1660, 1927, p. 53-54) (grifos nossos)

A menção feita a um parto seguido de hemorragia permite uma breve incursão na obra Materia Medica Misionera, já referida neste artigo. Nela, encontramos uma menção ao "pão porcino", planta empregada para combater veneno de cobras, para purgar a fleuma [um dos quatro humores] ou provocar a menstruação: "Proboca el mestruo a ora se beba o se apliq. a la natura dela mujer atada su rais al muslo isquierdo dicen acelera el parto" (MONTENEGRO, [1710], 1790, p. 123) (grifos nossos). Apesar de parecer um tanto curiosa a orientação de que não era necessária sequer a ingestão da planta para que essa provocasse o efeito esperado - desde que a raiz fosse amarrada na coxa esquerda -, constatamos que procedimentos semelhantes a este eram largamente empregados na Europa, sendo recomendados por Dioscórides, autor que, como já referido, exerceu grande influência sobre Montenegro ${ }^{15}$. O irmão jesuíta não deixou, contudo, de advertir sobre a inadequação do consumo da planta por mulheres grávidas, pois ela poderia provocar o parto prematuro ou mesmo o aborto. Em relação aos procedimentos adotados pelas parteiras, vale resgatar o registro feito por Montenegro sobre o uso do tabaco durante os partos:

La raíz del o mascando un pedacito con una pupada de ancho la muger que no puede echar la criatura muerta o viva, tragando el sumo de ella echa luego todo lo tenido sino es que este tan atrabesada la criatura que no pueda salir sin que la revuelvan, y esto hace con mayor eficacia y prestesa si la partera masca otro pedaso de rais y con aq.ella saliva le da uncion en los y jares y quadriles ala paciente al mismo tpô. q.e ella traga la saliva de la rais que ella masco 
poniéndola en pie para q.e salga la criatura. (MONTENEGRO, [1710], 1790, p. 188) (grifos nossos)

A menção feita à ajuda prestada pela parteira, mascando tabaco e ungindo os quadris da parturiente com saliva, revela não apenas a manutenção de práticas tradicionais largamente adotadas pelos indígenas - mesmo antes de serem reunidos nas reduções jesuíticas -, como o papel que as mulheres viriam a desempenhar no atendimento de gestantes e de doentes nas enfermarias e nos hospitais nelas instalados. Sabe-se que, ainda hoje, em alguns grupos indígenas, as mulheres "[...] ayudan con palabras de ánimo, masajes, unciones, infusiones y té a base de ys ji y yyychĩ, "planta que machacada se torna gomosa y resbaladiza', atributos que supuestamente facilitan el parto". Em relação às parteiras, são

[...] reconocidas por su habilidad en reencajar la criatura en los últimos días del embarazo, haciendo que el o la bebé nazca 'de cabeza' y no 'de pie' [...] el trabajo de parto se hacía en una casita separada, construida para ese fin y proveída de fuego (CHAMORRO, 2009, p. 266-267).

Mas, não apenas as indígenas parteiras observavam e mantinham práticas tradicionais nas reduções, também as gestantes parecem ter seguido à risca o cumprimento das funções sociais e, consequentemente, dos afazeres que lhes cabiam, indepen dentemente da sua condição de gestantes ou parturientes, ${ }^{16}$ como depreende-se deste relato em que o padre informa que "Una de ellas sufrió tan crueles dolores que si revolcaba en el suelo, como fuera de sí; pero apenas tocó una medalla con la efigie de San Ignacio y San Francisco Javier, cuando al instante sanó, dedicándose luego a sus quehaceres", enquanto que outra "[...] estando en el campo fue llevada al pueblo fuera de sentidos. Invocaron entonces al Santo Patriarca, aplicando a la enferma algunas reliquias suyas; después de lo cual recobró la salud (CARTAS ÂNUAS 1652-1654, 1927, p. 53) (grifos nossos).

As inúmeras referências a complicações surgidas durante partos que encontramos nas Ânuas da segunda metade do século XVII se mantêm nas Ânuas da primeira metade do século XVIII, como 
"Esto es lo que yo buscaba [...] el conocimento...

pode-se constatar na passagem a seguir e na qual ficam evidentes as críticas de alguns missionários à atuação das parteiras indígenas:

Hay que mencionar en este lugar también una gracia, alcanzada por reliquias de San Ignacio. En una estancia vecina estaba gravemente enferma de parto la esposa de Don Alonso de Alfaro. Duró ya 10 días este tormento, por la mala colocación de la criatura y la ignorancia de la partera. Ya había recibido los últimos sacramentos aquella señora, y su única congoja era el peligro de la criatura de morir sin bautismo. Al saber del caso el Padre Rector Sebastián de San Martín, envió a la enferma unas reliquias de San Ignacio, alentándola a la confianza de un buen parto. $\mathrm{Y}$ en realidad, al acercarse a la enferma las reliquias, cobró ella nuevas fuerzas, y nació un niño llorando débilmente. No podía vivir por el destrozo de su craneo. Fue bautizado en seguida, y al tercer día voló su alma al cielo. (CARTAS ÂNUAS 1720-1730 [1927], p. 79) (grifos nossos)

Em outro registro, encontramos menção à necessidade de ser realizada uma cirurgia, devido à grave enfermidade da parturiente:

Un caso muy singular hubo el año de 1722 en el pueblo de Jesús. Hubo alli una señora embarazada de seis meses, tan gravemente enferma, que estaba ya para morir. Toda la familia estaba afligida, y ella más que todos, y esto por la única razón de que se le muriese su hijo por nacer, sin alcanzar el bautismo. Habiase, en previsión de esto, preparado todo para una operación cirúrgica, que se iba a hacer luego muerta ella, para tentar el bautismo de la criatura. Dios le inspiró un remedio más eficaz. Confesóse, y pusóse después la medalla de San Ignacio, poniendo su confianza en él. No se engañó; pues, apenas puesto la medalla, pudo dar a luz. a la criatura, la cual sin demora fue batizada. Con esto se tranquilizó la enferma, y murió plácidamente en el Señor. (CARTAS ÂNUAS 1720-1730 [1927], p. 159). (grifos nossos)

Bastante ilustrativos da manutenção de saberes e práticas nativas relacionadas aos partos ou aos abortos nas reduções são 
os registros que dão conta de que os familiares de uma parturiente já haviam indicado uma série de remedios, para que os fetos mortos fossem expelidos, e que, por não terem alcançado êxito, recorressem ao padre, para que administrasse os sacramentos à moribunda:

Había llegado a un peligro extremo de su vida cierta señora, madre de unos gemelos mellizos, muertos antes de su nacimiento, sin que ella le pudiera dar a la luz, no obstante de todos los remedios que le habian aplicado sus parientes y conocidos. Ya que ella estaba para espirar, se llamó a uno de nuestros Padres, para administrarle los últimos sacramentos. Despues de haber cumplido con su sagrado deber, aconsejó el a la enferma, ya que no resultaron eficaces los remedios humanos, que acudiese a los divinos. Replicó le el Padre que acudiese con confianza a la protección de nuestro santo patriarca San Ignacio, cuyo socorro en casos de difícil parto era un hecho reconocido en todo el mundo, y prometió enviarle del colegio el reliquario con la firma manuscrita del Santo, para facilitarle la debida fe y confianza [...] aplicándose aquella santa reliquia [...] dio ella la luz las criaturas y libróse con eso del inminente peligro de muerte con gran admiración de los de su familia. (CARTAS ÂNUAS 1730-1735 [1927], p. 52) (grifos nossos)

Em outro registro, tanto a criança quanto a mãe foram salvas pela intercessão de uma relíquia de Santo Inácio: 'Sufrió otra mujer de semejantes angustias de parto, aplicó el mismo papel firmado, $y$ dio a luz con bien a una criatura viva aunque ya se habia acudido al sacerdote, para que le asistiese en la hora de la muerte" (CARTAS ÂNUAS 1730-1735 [1927], p. 53) (grifos nossos). Santo Inácio parece ter sido, de fato, bastante invocado em situações de iminência de abortos ou durante as complicações surgidas durante o parto, pois "Durante una epidemia en las regiones del Paraná y Uruguay habia muchos abortos, que casi todos alcanzaron el bautismo, debido a una especial protección de San Ignacio, cuya medalla se cuelgan del cuello las madres, tan pronto que sienten habia llegado su hora” (CARTAS ÂNUAS 1730-1735 [1927], p. 140) (grifos nossos).

A alta incidência de abortos em decorrência das epidemias é também relatada pelo Padre Cardiel, na Carta Relação de 1747. A 
"Esto es lo que yo buscaba [...] el conocimento...

situação, segundo ele, acabou por colocar os padres diante de um dilema, já que algumas gestantes, após contraírem varíola, morriam um pouco antes do parto, sem que seus bebês fossem batizados. Preocupados em garantir o batismo aos bebês que estavam por nascer, muitos missionários ofereciam às gestantes alguns goles de vinho com pimenta moída [um preparado com propriedades abortivas] para que o parto fosse apressado e o recém-nascido pudesse ser batizado, para salvação de sua alma. A adoção deste procedimento, em várias das reduções jesuíticas, teria suscitado, segundo Cardiel, um intenso debate na Universidade de Córdoba, após o qual ficou estabelecido que: ' $Y$ vistas todas las circunstancias y disposiciones, respondieron los Doctores que atentas las circunstancias, non erat directe procurare abortum, non erat intrinsece malum, y por consiguiente erat licitum. Con cuya respuesta se quitó el escrúpulo en otros pueblos y se lograron muchas almas" (CARDIEL apud FURLONG, 1953, p. 212-213) (grifos nossos).

Como pudemos constatar na análise que fizemos da obra Matéria Medica Misionera e na consulta a obras clássicas de Medicina adotadas no século XVII e XVIII, tanto europeus quanto indígenas conheciam uma infinidade de plantas e procedimentos que favoreciam o aborto, garantiam a continuidade da gravidez e, também, um bom parto. É muito provável que os jesuítas boticários dos colégios e das reduções e, até mesmo aqueles que atuavam como enfermeiros ou médicos, conhecessem as propriedades abortivas das plantas nativas americanas e daquelas que passaram a ser cultivadas nos herbários mantidos pelos missionários. Vale lembrar, também, que, dentre as recomendações feitas pelo padre José Cardiel aos missionários que se dirigiam a América, em 1747, estava a de que trouxessem alguns livros, inclusive um de "medicina casera" (CARDIEL apud FURLONG, 1953, p. 212-213), o que poderia explicar o conhecimento e o uso de preparados abortivos, bem como de procedimentos indicados, tanto para favorecer a expulsão dos fetos [em consequência de abortos] e para contornar dificuldades surgidas durante o parto quanto para amenizar as dores no período pós-parto. 


\section{Considerações finais}

Preocupados em melhor atender os doentes, muitos dos missionários jesuítas enviados a América, apesar de não serem "especialistas en la ciencia de Galeno y en Farmacopea", dedicaram-se à coleta e a experimentos com plantas nativas existentes nas imediações dos colégios e das reduções em que atuavam. Contando com a colaboração de indígenas - que desempenharam ativamente o papel de informantes, enfermeiros e, também, de copistas ${ }^{17}-$ irmãos e padres jesuítas - como Pedro de Montenegro e Segismund Asperger - instalaram herbários e boticas, bem como sistematizaram e fizeram circular saberes e práticas, através da intensa correspondência que mantiveram entre si ou das cópias de tratados e receituários que fizeram circular entre as reduções e os colégios das Províncias Jesuíticas da América meridional e aqueles instalados na Europa. ${ }^{18}$

A cópia manuscrita do tratado Materia Medica Misionera, com data de 1790, que localizamos no Acervo do Instituto Anchietano de Pesquisas da Unisinos, parece confirmar a circulação de cópias de obras desta natureza entre os diferentes espaços de atuação da Companhia de Jesus na América. A versão que analisamos não conta com os desenhos presentes no original, e seria, segundo anotação feita a mão por Bartomeu Meliá, "[...] manuscrito [que] parece ser de la época y está escrito por quien no domina la lengua castellana, y asi podría ser un indio misionero" (MELIÁ, 1986). Sabe-se que uma cópia do texto de Pedro de Montenegro - Libro primeiro de la propiedad y birtudes de los arboles i plantas de las misiones y provincias de Tucumán con algunas del Brasily del Oriente - encontra-se guardado na Biblioteca Nacional de Madri. Recentemente, um manuscrito, intitulado Curiosidad - un libro de medicina escrito por los jesuitas en las misiones del Paraguai, foi localizado na Biblioteca Nacional do Rio de Janeiro. Ao analisá-lo, Heloísa Gesteira constatou que os dois textos traziam "partes idênticas", o que a fez levantar "[...] a hipótese de que trabalhos deste tipo eram compartilhados pelos missionários" e que o documento depositado na Biblioteca Nacional do Rio de Janeiro seria "uma reprodução do texto de Montenegro" (GESTEIRA, 2006, p. 2-3). A existência de cópias manuscritas deste mesmo texto foi também observada por Pedro Arata, que, em artigo de 1898, afirmou que "[...] las copias del 
"Esto es lo que yo buscaba [...] el conocimento...

libro del Hermano Montenegro deben haber sido muchas, y repartidas en el Paraguay, en las Misiones y aun en Europa" (ARATA, 1898, p. 435).

Como pode-se constatar, os indígenas contribuíram também para a difusão e a circulação dos conhecimentos - relativos às propriedades curativas de plantas nativas - cuidadosamente sistematizados pelos missionários jesuítas. Encarregados das cópias de cartilhas com orientações para evitar o contágio, de fórmulas de medicamentos e de obras de medicina, muitos desses indígenas copistas não apenas favoreceram a troca e a disseminação de uma série de saberes e práticas de cura entre as distintas e distantes terras de missão da Companhia de Jesus, como "[...] libertar[an] de la muerte un gran número de personas [...]” (ARATA, 1898, p. 443).

\section{"ESTO ES LO QUE YO BUSCABA [...] EL CONOCIMIENTO DE LAS YERBAS, Y SU APLICACIÓN": SYSTEMATIZATION AND DIFFU- SION OF THE KNOWLEDGE ON THE VIRTUES OF MEDICINAL PLANTS (SOUTH AMERICA, SEVENTEENTH AND EIGHTEENTH CENTURIES)}

Abstract: This article presents the significant process of cultural exchanges that took place between Indians and Jesuit missionaries in South America in the seventeenth and eighteenth centuries, with emphasis on the knowledge regarding medicinal plants and healing practices. The analysis of the Annual Letters of the Jesuit Province of Paraguay and the Materia Medica Misionera work, written by Jesuit brother Pedro de Montenegro in 1710, revealed the important role played by informants, nurses and indigenous scribes, in the identification, collection, and experimentation with native plants, as well in the diffusion and circulation of medical knowledge systematized by the missionaries of the Society of Jesus. Keywords: Society of Jesus, Annual Letters, cultural mediators, Indian Pharmacopoeia, Materia Medica Misionera.

\section{Notas}

${ }^{1} \mathrm{Na}$ Europa, os métodos mais empregados eram a purga e a sangria, além de unguentos mercuriais, do pó de unicórnio, do milagroso bezoar e das inúmeras beberagens, cujos ingredientes imprescindíveis eram o vinho e o azeite, tão em voga na Medicina do Renascimento.

Anos 90, Porto Alegre, v. 19, n. 35, p. 419-444, jul. 2012 
${ }^{2}$ Sabe-se que, além das boticas, os jesuítas mantiveram herbários junto aos colégios e às reduções. A precariedade com que era realizado o transporte e as condições em que chegavam os medicamentos vindos da Europa motivaram os missionários a conhecerem melhor a flora americana e suas possíveis utili-dades no atendimento dos enfermos. É preciso, no entanto, ressaltar que plantas medicinais europeias, como o alecrim, a menta, o cominho, a camomila e a losna também foram cultivadas nos herbários dos colégios e nas reduções jesuíticas.

${ }^{3}$ É preciso considerar que, durante o século XVIII, “[...] la fructifera relación de la química y la medicina iniciarán un proceso de cambio en la farmacología y jugaron un papel fundamental en el terreno terapéutico. A partir de entonces se produjo uma larga Carrera entre quimicos, farmacéuticos y médicos para encontrar componentes realmente activos de los extractos vegetales." (PAGE; FLACHS, 2010, p. 121).

${ }^{4}$ Escrita no ano de 1710, a obra tem 458 páginas, além de 148 desenhos de plantas feitos a mão, e conta em seu frontispício com uma imagem de Nossa Senhora das Dores, padroeira dos doentes. Neste artigo utilizamos uma cópia manuscrita do ano de 1790, disponível para consulta no Acervo do Instituto Anchietano de Pesquisas da Unisinos, e também a versão de uma edição argentina, de 1945, disponível na Biblioteca Virtual del Paraguay. No exemplar manuscrito que consultamos no IAP, há uma breve anotação feita a mão por Bartolomeu Melià e datada de 1986: "El presente manuscrito parece ser de la época y está escrito por quien no domina la lengua castellana, y asi podría ser un indio misionero." Esta observação parece confirmar a hipótese levantada por Heloísa Gesteira de que estes textos eram copiados [pelos próprios missionários ou, então, por copistas indígenas], distribuídos e compartilhados pelos inacianos instalados em várias regiões atendidas pela Companhia de Jesus [daí, trazer os nomes das espécies de plantas em espanhol, tupi e guarani], conformando uma "rede de troca de experiências e de informações" e um "processo de cosmopolitização das práticas médicas, que, por sua vez, era acompanhada por um processo de experimentação, cultivo e disseminação de plantas." (GESTEIRA, 2006, p. 5).

${ }^{5}$ Pedro de Montenegro nasceu na Galícia, em maio de 1663, e, ainda jovem provavelmente, em 1679 -, iniciou seus estudos de medicina no "Hospital General de Madrid", tendo ingressado na Companhia de Jesus em abril de 1691. No Catálogo da Província do ano de 1703, consta que o irmão Montenegro "[...] había hecho los últimos votos el 25 de abril de 1703, que se allaba en las Misiones del Rio Paraná, que sus fuerzas físicas eran 'débiles' y su oficio era el de cirujano (Chirurgus)" (FURLONG, 1947, p. 67). Considerando a formação que Pedro de Montenegro teve na Espanha e os procedimentos terapêuticos empregados pelos médicos e cirurgiões à época - que previam sangrias, ingestão de ervas medicinais, fricções, aplicação de ventosas e emplastros com os mais variados ingredientes e cataplasmas, bem como amputações e correções de desvios ósseos - e o ofício de cirurgião a ele 
atribuído no Catálogo, pode-se inferir quais as atividades que viria a desempenhar nas missões da Companhia de Jesus na América.

${ }^{6} \mathrm{O}$ grego Dioscórides é considerado o fundador da Farmacognosia, através da sua obra De Matéria Médica, considerada um clássico da Farmácia e da Botânica médica no século XVI. A obra está dividida em cinco livros, que descrevem cerca de 600 plantas, 35 fármacos de origem animal e 90 de origem mineral, dos quais cerca de 130 já apareciam no Corpus hippocraticum.

${ }^{7}$ Em relação a este aspecto, deve-se, inegavelmente, “[...] valorizar o esforço de coleta e sistematização do conhecimento médico por parte dos inacianos", mas tendo consciência de que "tal iniciativa era feita a partir dos referenciais da cultura erudita do período, sendo os estudos sobre as virtudes das plantas e animais realizados a partir dos referenciais da História Natural e da Medicina hipocrática." (GESTEIRA, 2006, p. 1).

${ }^{8}$ A obra conta com cinco capítulos, sendo as três primeiras partes direcionadas às nomenclaturas e propriedades das plantas, às orientações quanto ao tempo certo para seu recolhimento e às suas virtudes. O quarto capítulo apresenta, detalhadamente, ervas, raízes e cascas que deveriam ser administradas em determinadas enfermidades. De acordo com G. Furlong, a quinta parte, intitulada "Otras curiosidades e recetas útiles", não teria sido escrita por Montenegro. (1962, p. 611)

${ }^{9} \mathrm{O}$ exercício da Medicina na Espanha - e, posteriormente, na América, no México (1546) e em Lima (1570) - era regulamentado pelo Protomedicato que concedia a licença necessária para o desempenho da profissão. As regras de seu funcionamento foram definidas somente durante o reinado de Felipe II (1527-1598), período em que foram instaladas cátedras nas universidades e criados hospitais para o fomento dos estudos de Medicina. Sabe-se que existiam três categorias de médicos à época: o doutor (aquele que havia completado seus estudos na universidade), o licenciado (autorizado a exercer a medicina ou a cirurgia, dentre os quais se destacavam os práticos) e o médico militar. À margem destas categorias, encontravam-se os boticários (encarregados da preparação e venda de medicamentos) e os sangradores.

${ }^{10}$ Montenegro afirma que, ao longo dos 21 anos de atuação como missionário na América meridional, havia entrado em contato com apenas um médico e um cirurgião formados.

${ }^{11}$ As camaras de sangre consistiam em diarreia acompanhada de sangue.

${ }^{12}$ Sobre a temática, ver FLECK, Eliane Cristina Deckmann. Em memória de São Tomé: pegadas e promessas a serviço da conversão do gentio (séculos XVI e XVII). Estudos Ibero-Americanos, v. 36, p. 01-30, 2010.

${ }^{13}$ As Cartas Ânuas tinham como base os relatórios anuais que o Provincial recebia dos superiores das residências, dos colégios, das universidades e missões junto aos índios, sendo redigidas pelos secretários ou por pessoas com capacidade para 
escrevê-las, designadas pelo Provincial. Vale lembrar que cabia a esta correspondência unir, por meio da escrita, os diversos e esparsos membros da Companhia de Jesus, promover uma propaganda edificante que inspirasse novas adesões e, ainda, compartilhar as experiências alcançadas, de maneira a tornar as missões mais frutíferas pela troca de informações.

${ }^{14}$ A primeira Instrução, que data de 1609, teve como destinatários os padres José Cataldino e Simão Maceta, missionários enviados ao Guairá. A segunda, de 1610, foi dirigida a todos os missionários jesuítas que atuavam entre os indígenas do Guairá, do Paraná, e entre os indígenas guaicurus, e recomendava que: "No sitio mais apto façam a Redução e a povoação [...]. Nisso advertirão primeiro que tenha água, pescaria, boas terras e que estas não sejam todas alagadiças, nem muito quentes, mas que tenham bom clima e se apresentem sem mosquitos e isentas de outros incômodos [...]" (Apud RABUSKE, 1978, p. 24).

${ }^{15}$ Dentre as obras de medicina atribuídas a Pedro Hispano - formado pela Univer-

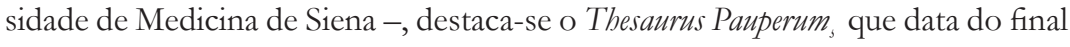
do século XIII e reúne orientações de autores clássicos da Medicina sobre vários temas e que continuavam sendo adotadas no século XVII e XVIII. Numa breve consulta à edição de 1973 desta obra, patrocinada pela Universidade de Coimbra, localizamos, no capítulo XLVI e XLVII, intitulados Contra a dificuldade no parto e $A$ dor depois do parto, respectivamente, uma série de procedimentos - recomendados por Dioscórides - a serem adotados durante complicações de parto. Algumas das orientações atribuídas a ele e compiladas por Pedro Hispano - ou Papa João XXI - são: 'Item 17 - atando serpentária às virilhas da parturiente, imediatamente dará à luæ; item 18 - aplicar um emplastro quente de artemísia cozido em água, e imediatamente expele o feto e as secundinas; Item 33 - atar à coxa raiz de ciclame faz dar à luz mais cedo; e, se a mulher passar por cima dessa raiz, terá um aborto; dar a beber a erva ou a flor da violeta branca provoca a menstruação depois do parto, extrai a criança morta e destrói a viva; item 34 - aplicar folhas de madressilva põe fora o parto; mas retirem-se logo, não vão arrastar a madre [o útero]; bebê-las expele o feto vivo ou morto e as secundinas". (PEREIRA, 1973, p. 276) (grifos nossos). É plausível supor que, as inúmeras situações de complicações de parto que Montenegro presenciou ou, então, as informações que obteve de outros indígenas sobre o trabalho das parteiras, tenham favorecido a descrição de plantas nativas americanas com propriedades muito similares às que eram amplamente utilizadas na Europa, tais como a serpentária, a artemísia, o ciclâmen, a flor-de-violeta-branca e a madressilva, referidas por Dioscórides. ${ }^{16}$ Sabe-se que sobre as mulheres indígenas recaíam precauções, interdições e resguardos específicos durante gravidez e no período após o parto. Muitas delas - como as Payaguá - costumavam dar a luz sem a ajuda de outras mulheres, exceto quando houvesse complicações ou as dores aumentassem; outras, como as mulheres Lengua, "[...] a continuación de él[o parto] no dejan de hacer sus trabajos 
ordinários"(AZARA, [1809], 1998, p. 71). O padre Martin Dobrizhoffer é enfático ao afirmar que para os Abipone, "[...] el parto da menos trabajo a las parturientas que a sus maridos", pois, logo após o nascimento da criança, o pai afastava-se de qualquer esforço físico (DOBRIZHOFFER, [1783-1784], 1967-1970, t. 2, p. 211). Já o padre Paucke registrou que, entre os homens Mocovi, tão logo se iniciassem as dores do parto, o pai da criança que estava por nascer se isolava "[...] como si él estuviere enfermo a la muerte", cabendo à parturiente "cocinarle y darle bien de comer" (PAUCKE, [1749-1767], 1943, p. 222).

${ }^{17}$ De acordo com E. Neumann, o domínio do alfabeto pelos indígenas foi uma decorrência da catequese, que permitiu que atingissem notável destreza nas práticas letradas, participando diretamente na elaboração de vocabulários, catecismos, gramáticas e na reprodução [cópias] de obras que passavam a circular entre os colégios e as reduções. Diz ele: "A escrita indígena, registrada em diferentes suportes e com finalidades diversas, obriga-nos a rever em grande medida as avaliações simplistas que consideravam a atividade 'escriturária' como um fato menor ou mesmo restrita aos textos canônicos nas reduções [...] Os testemunhos da prática escriturária indígena missioneira [...] encontram-se em arquivos sul-americanos ou europeus [...]." (NEUMANN, 2005)

${ }^{18}$ Heloísa Gesteira defende que estes textos eram copiados [pelos próprios missionários ou, então, por copistas indígenas], sendo distribuídos e compartilhados pelos inacianos instalados em várias regiões atendidas pela Companhia de Jesus [daí, trazer os nomes das espécies de plantas em espanhol, tupi e guarani], conformando uma "rede de troca de experiências e de informações" e um "[...] processo de cosmopolitização das práticas médicas, que, por sua vez, era acompanhada por um processo de experimentação, cultivo e disseminação de plantas." (GESTEIRA, 2006, p. 5).

\section{Referências}

ARATA, Pedro N. Botánica Médica Americana. Los Herbarios de las Misiones del Paraguay. La Biblioteca, ano II, t. VII, Buenos Aires, 1898.

AZARA, Felix de. Viajes por la América meridional, Tomo II, Buenos Aires: El Elefante Blanco, 1998.

CARTAS ÂNUAS DE LA PROVÍNCIA DEL PARAGUAY. C. A. 1650-1652. Transcrição de Carlos Leonhardt, SJ., Buenos Aires, 1927. Cópia disponível no Arquivo do Instituto Anchietano de Pesquisas. Unisinos, São Leopoldo. 


\section{Eliane Cristina Deckmann Fleck, Roberto Poletto}

CARTAS ÂNUAS DE LA PROVÍNCIA DEL PARAGUAY. C. A. 1652-1654. Transcrição de Carlos Leonhardt, SJ., Buenos Aires, 1927. Cópia disponível no Arquivo do Instituto Anchietano de Pesquisas. Unisinos, São Leopoldo.

CARTAS ÂNUAS DE LA PROVÍNCIA DEL PARAGUAY. C. A. 1659-1660. Transcrição de Carlos Leonhardt, SJ., Buenos Aires, 1927. Cópia disponível no Arquivo do Instituto Anchietano de Pesquisas. Unisinos, São Leopoldo.

CARTAS ÂNUAS DE LA PROVINCIA DEL PARAGUAY. C. A. 1720-1730. Transcrição de Carlos Leonhardt, SJ., 1927. Cópia disponível no Arquivo do Instituto Anchietano de Pesquisas. Unisinos, São Leopoldo.

CARTAS ÂNUAS DE LA PROVINCIA DEL PARAGUAY. C. A. 1730-1735. Transcrição de Carlos Leonhardt, SJ., 1927. Cópia disponível no Arquivo do Instituto Anchietano de Pesquisas. Unisinos, São Leopoldo.

CHAMORRO, Graciela. Decir el Cuerpo - Historia y etnografía del cuerpo en los pueblos Guaraní. Asunción: Tiempo de Historia, Fondec, 2009.

DI LISCIA, María Silvia. Saberes, Terapias Y Prácticas Médicas em Argentina (17501910). Madrid: Consejo Superior de Investigaciones Científicas. Instituto de Historia, 2002.

DOCUMENTOS PARA LA HISTORIA ARGENTINA - D.H.A. (Cartas Ânuas de la Província del Paraguay, Chile y Tucumán de la Província de la Compañía de Jesús). 1615-1637, Tomo XX, Buenos Aires, Talleres Casa Jacobo Preuser, 1927.

DOBRIZHOFFER, Martin. História de los Abipones, Resistencia: Universidad Nacional del Nordeste, 1967-1970.

ECHENIQUE, Nora Inês; FERREIRA, Miriam Mirabel. La Medicina en las Reducciones Jesuíticas. V Simpósio Nacional de Estudos Missioneiros. Anais. Santa Rosa, Faculdade de Filosofia, Ciências e Letras Dom Bosco, p. 251-262, 1985.

FLECK, Eliane Cristina Deckmann. Em memória de São Tomé: pegadas e promessas a serviço da conversão do gentio (séculos XVI e XVII). Estudos IberoAmericanos, v. 36, p. 01-30, 2010.

FURLONG, Guillermo. Misionesy sus Pueblos de Guaranies. Buenos Aires: Ediciones Theoria, 1962. . José Cardiely su Carta Relación (1747). Buenos Aires, Librería del Plata, 1953.

1947. - Medicos Argentinos durante la dominación hispanica. Buenos Aires. Huarpes, . Bibliotecas Argentinas hasta la dominación hispanica. Buenos Aires: Huarpes, 1944. 
"Esto es lo que yo buscaba [...] el conocimento...

GESTEIRA, Heloísa Meireles. Manuscritos Médicos e circulação de idéias nas missões jesuíticas na América. Anais Eletrônicos. VII Encontro Internacional da ANPHLAC, Campinas, 2006, p. 01-08.

HERNÁNDEZ, Pablo S. J. Organización Social de las Doctrinas Guaranies de la Compañia de Jesús. Barcelona: Gustavo Gili Editores, 1913.

MONTEnegro, Pedro. Materia Medica Misionera. [1710], 1790. Manuscrito disponível no Arquivo do Instituto Anchietano de Pesquisas - Unisinos, São Leopoldo.

- Materia Medica Misionera. Buenos Aires: Edición de la Biblioteca Nacional de Buenos Aires, 1945.

MUHN, J. La Argentina vista por viajeros del siglo XVIII. Buenos Aires: Huarpe, 1951.

NEUMANN, Eduardo S. Práticas letradas guaranis: produção e usos da escrita indígena (séculos XVII e XVIII). Tese (Doutorado). Programa de Pós-Graduação em História UFRJ, 2005.

PAGE, Carlos; FLACHS, Maria Cristina Vera de. Textos Clásicos de Medicina en la Botica Jesuítica del Paraguay. Cuadernos del Instituto Antonio de Nebrija, Madrid, v. 13, p. 117-135, 2010.

PAUCKE, Florián. Hacia allá y para acá. Una estadía entre los indios mocobies (17491767), tomo II, Tucumán: Universidad Nacional de Tucumán, 1943.

PEREIRA, Maria Helena da Rocha. Obras Médicas de Pedro Hispano. Coimbra: Acta Universitatis Conimbrigensis, 1973.

RABUSKE, Arthur S. J. A Carta Magna das Reduções Jesuíticas Guaranis. Estudos Leopoldenses. São Leopoldo, v. 14. n. 47, p. 21-39, 1978.

SEPP, Antonio S. J. Viagem às missões jesuíticas e trabalhos apostólicos. São Paulo: Editora da Universidade de São Paulo, 1980.

Recebido em: 13/11/2011

Aprovado em: 14/05/2012 